DOI: $10.20287 /$ doc.d24.en01

\title{
Entrevista con Diego Rísquez: fragmentos de la imagen de Bolívar en Manuela Sáenz, la Libertadora del Libertador (2000)
}

\author{
Rafael Arreaza Scrocchi*
}

Lugar y fecha de la entrevista: entre noviembre y diciembre del año 2016 por medio de varias conversaciones que tuve con Diego Rísquez quien estaba en su casa en Caracas, Venezuela.

Rafael Arreaza Scrocchi: Diego, tu película Manuela Sáenz: La Libertadora del Libertador (2000), tiene una narrativa epistolar muy apegada a lo que Simón Bolívar le escribía a Manuela Sáenz y viceversa. En varias escenas incluyes fragmentos exactos de las apasionadas líneas que le escribió el Libertador a su Libertadora. El juego de la trama se transforma por momentos en una especie de melodrama que transita entre los deberes de Bolívar como jefe de estado, hasta los placeres de Bolívar con Manuela Sáenz. ¿Podrías explicarnos un poco más al respecto?

Diego Rísquez: La imagen del Libertador en el film Manuela Sáenz tiene una connotación totalmente diferente a la imagen del Bolívar de mi película en Súper 8, Bolívar Sinfonía Tropikal (1980). En primer lugar, la trama del film Manuela Sáenz está enfocada en lo que fue el desenlace de la relación íntima que existió entre el Libertador y la Libertadora del Libertador, como la llamó el mismo Bolívar. En este film Bolívar es además tomado en cuenta durante los años más difíciles de su carrera militar y de su vida personal. Las guerras, los decretos, las doctrinas, las cartas dictadas por Bolívar, las decisiones tomadas por el Libertador y hasta los resultados de ciertas confrontaciones entre los españoles y el ejército bolivariano, reflejan algo relacionado con la presencia de Manuela en la vida personal de Bolívar. Hay una especie de contraposición entre lo que sería observar la imagen de Bolívar como el héroe de la independencia, y observar la imagen de Bolívar a través de la perspectiva de Manuela Sáenz. A mí me gusta mucho jugar con la psicología de mis personajes y por esto se puede observar como la trama gira en torno a una especie de relación amorosa muy apasionada y la vez muy tumultuosa. Esto es lo que se puede leer a través de las cartas que intercambiaron Bolívar y Manuela. Descripci-

* Vrije Universiteit Brussel - VUB, Faculty of Arts and Philosophy, Department of Language and Literature, Centre for Literary and Intermedial Crossings. 1050, Bruxelles, Belgium. E-mail: Rafael.Arreaza-Scrocchi@vub.be 
ones geográficas, la guerra y sus resultados, las aspiraciones de Bolívar y sus deseos de ver a Manuela, son algunas de las cosas que el Libertador le escribía a Manuela Sáenz. Esto es parte de la historia real y de la re-imaginada en mi película.

R.A.S.: La imagen de Bolívar refleja efusividad, pasión, melancolía y perspicacia. ¿Cómo lograste amalgamar todos estos aspectos para poner en escena a un Libertador distinto al que ya se había representado en el pasado como el Bolívar de Miguel Contreras Torres en 1942 por el actor mexicano Julián Soler, o por el Bolívar del italiano Alessandro Blasetti en 1969 por el actor Maximilian Schell?

D.R.: Sí, Bolívar aquí es una especie de mosaico en el que se observan las distintas etapas de sus días con Manuela. Afortunadamente, logramos trabajar con un actor extraordinario, Mariano Álvarez, actor conocidísimo en el medio televisivo y teatral en Venezuela y en el exterior también. Mariano Álvarez tenía ya experiencia con el papel de Bolívar cuando interpretó al Libertador en una miniserie que salió por allá en 1982 durante el bicentenario del natalicio de Bolívar. La directora Betty Kaplan estuvo a cargo del proyecto en donde Mariano hizo un papel maravilloso actuando como Bolívar desde sus días en París en 1802 hasta su muerte en 1830. En el caso de Manuela, trabajamos con la actriz cubana, Beatriz Valdez, quien también tenía una trayectoria cinematográfica internacional, y quien además realizó un papel fascinante actuando como Manuela Sáenz. Hubo mucha energía positiva en el set durante la grabación del film, y Mariano y Beatriz realzaron las cualidades de los personajes para hacernos ver los detalles más intensos de lo que la relación entre Bolívar y Manuela debe haber sido.

R.A.S.: ¿Podría decirse que la imagen de tu Bolívar en este film representa además una figura quizás un poco más fácil de digerir visualmente ya que la trama es quizás un poco más común y parecida a la conocida imagen de un Libertador obsesionado por Manuela? Te pregunto esto porque el Libertador de tu película Bolívar Sinfonía Tropikal (1980) está totalmente desligado a este nuevo tipo de representación cinematográfica de Bolívar.

D.R.: Efectivamente. Es una trama y un Bolívar totalmente diferente. Yo quería hacer un film opuesto a mi trilogía, a lo que yo acostumbro a realizar mezclando la iconografía, las artes plásticas y lo surrealista. Con Manuela quise hacer un film para todo tipo de espectador, sencillo de entender y con muy poco uso de lo subliminal. Es muy poco lo subliminal en este film, sin embargo, la relación entre Bolívar y Manuela ya de por sí deja muchas incóg- 
nitas. El film gira en torno a esto, a la perenne reflexión de Manuela pensando en su Bolívar.

R.A.S.: Interesante. La película tiene además muchas conexiones con tu film Bolívar Sinfonía Tropikal (1980). Por ejemplo, el uso de las tomas panorámicas del mar Caribe al inicio y al final, los paisajes bucólicos, la selva, la sierra, la sabana, las montañas, pero sobre todo, la constante introspección del protagonista principal hurgando en los eventos pasados a través del subconsciente siempre frente al océano. Estos eventos tienen mucha similitud en tus películas. ¿Qué puedes compartir al respecto?

D.R.: Desde mis inicios como aficionado al cine y a las artes plásticas siempre estuve cautivado por las tomas panorámicas reflejando el mar, las playas, la extensión, el color y la magnitud de la costa en Venezuela, un paisaje quizás único. Todos estos sitios que muestro los recorrió Bolívar. Yo siempre basé estas ideas en mis ensayos fotográficos, en tomas preconcebidas que yo había elaborado fotográficamente en el pasado. Te voy a dar unas fotos para que las incluyas aquí y puedas observar cómo surgieron varias de las escenas de mis películas.

R.A.S.: Gracias, Diego. Otra interesante cuestión sería ver cómo a través de Manuela la trama de la película invita al espectador a comprender la historia por medio de la alucinación al igual que el Libertador en Bolívar Sinfonía Tropikal (1980). Los recuerdos de Manuela narran lo que vivió en el pasado con Bolívar de la misma forma como subliminalmente lo hiciste con el Dr. Reverend y Simón Bolívar en frente al mar Caribe. ¿Qué puedes comentar sobre este aspecto?

D.R.: Me gusta mucho narrar la historia de mis películas a través del recuerdo del personaje principal, por medio de la alucinación y de la agonía. Esto simplemente se debe a que en ese punto los recuerdos acompañan el destino final de Bolívar y el de Manuela. En el caso de Manuela Sáenz la película enfatiza la narración de una Manuela Sáenz ya casi moribunda viviendo con sus perros y con sus esclavas que la ayudaban a vender tabaco, a traducir cartas y a interpretar el destino de uno que otro marinero que pasaba a preguntarle por su historia con Bolívar. La imagen del Libertador aquí es un poco más efímera, es como una especie de acompañante a todo lo que cuenta Manuela, sin embargo, la figura mítica de Bolívar la basé primordialmente en la época más importante de la vida política y en los días finales de un Bolívar relacionado profundamente con Manuela. 
R.A.S: Sobre el estreno recuerdo haber escuchado que la película también fue proyectada en la Casona y que el presidente Chávez la vio junto a Fidel Castro. ¿Fue esto cierto?

D.R.: Sí. Resulta que el estreno de la película ocurrió durante un momento muy interesante ya que en Venezuela estaban ocurriendo muchos cambios en la sociedad en general. La llegada de la llamada revolución bolivariana auspiciada por Chávez, por ejemplo. César Miguel Rondón escribió algo al respecto, creo que salió publicado en la prensa. Casualmente el film se estrenó durante esta transición con la llegada de Chávez a la Casona. El mismo Chávez recomendó la película por cadena de radio y televisión luego de haberla visto con Fidel. La película sobre Manuela fue muy taquillera y tuvo una gran diseminación nacional e internacional.

R.A.S.: Interesante. Y con respecto al equipo de trabajo intelectual, sé que laboraste junto con el escritor y guionista Leonardo Padrón. Recuerdo haber leído que a él se le ocurrieron muchas de las ideas de la trama central y que tú lo ayudaste a encauzar todos estos detalles. ¿Puedes compartir algo al respecto?

D.R.: Claramente. Leonardo Padrón tenía una idea ya concebida sobre un boceto general que narraría la historia de la vida de Manuela Sáenz de atrás hacia adelante como se observa en el film con el inicio de las olas impactando las piedras en el puerto de Paita en 1856. Ambos elaboramos una historia que reunía sus elementos y los míos. Además, como te comenté anteriormente, los actores principales hicieron un papel extraordinario asimilando los distintos sucesos que tuvieron que reinterpretar en la gran pantalla.

R.A.S.: Me comentaste en otra oportunidad que antes de meterte de lleno en la escenografía, en la trama y en la psicología de tus personajes, te preparas intelectualmente leyendo mucho y observando mucha iconografía nacional. Me dijiste en una ocasión que la imagen preconcebida de tu Simón Bolívar cinematográfico tenía mucho que ver con la biografía del alemán Gerhard Masur, titulada: Simón Bolivar, y con la biografía titulada El Libertador, de Augusto Mijares. ¿De dónde surgió la imagen de Manuela Sáenz?

D.R.: Los libros de Masur y Mijares me ayudaron mucho a establecer la conexión entre Bolívar el héroe icónico y el Bolívar humano. Ambos autores analizan muy bien la vida de Bolívar como hombre de carne y hueso, quizás bastante desligados de lo que se lee comúnmente sobre el Libertador. El libro de Masur, un escritor alemán, tiene un punto de vista mucho más distante al de Mijares, historiador venezolano. Me gusta mucho el contraste entre estas dos 
obras y ambos forman parte de mi Bolívar en Bolívar Sinfonía Tropikal (1980). Ahora bien, con respecto a la imagen de Manuela, esto tiene que ver mucho con la idea que trajo Leonardo Padrón cuando nos reunimos por primera vez. Él me comento que estaba metido de lleno en la narración del libro Las cuatro estaciones de Manuela Sáenz del escritor alemán, Víctor W.von Hagen, y lo demás es historia, quiero decir, es lo que puedes ver en la película desde el principio en la playa, hasta el final con la muerte de Manuela en frente al mar.

R.A.S.: Diego, súbitamente apareces también de incógnito en el film, esta vez como mensajero montando a caballo, cabalgando con el mensaje que anuncia la muerte de Bolívar. ¿Cómo originas estas escenas?

D.R.: Yo salgo y actúo brevemente en todas mis películas. Es una especie de auto invitación a lo que he creado, a lo que estoy visualizando a través de la cámara. Hoy día pienso que esas fugases apariciones quedarán reflejadas en la historia de Rísquez el cineasta, el recreador de la iconografía nacional en la gran pantalla. Es también una especie de sello en la que participo con mi presencia mostrando lo inmiscuido que estoy en la trama.

R.A.S.: Entiendo. ¿Como la breve participación en la que actúas en tu penúltimo film Reveròn (2011) en donde haces el papel del doctor que visita a Reverón en el castillete y que le pide que repita el número 33 varias veces frente a Juanita?

D.R.: Exactamente. Escenas muy cortas.

R.A.S.: De igual manera apareces fugazmente en tu último biopic sobre Felipe Pirela. Aquí eres un sastre italiano y hasta cantas Volare. ¿Tomarías las riendas en un papel más largo?

D.R.: Sí, hago del sastre que viste a Pirela cuando va camino al estrellato, también algo muy breve. Con respecto a un papel principal ya lo hice en mis primeras películas, en la trilogía. A mí me gusta más estar detrás de cámaras reflexionando y creando las escenas, el escenario, los más mínimos detalles de las películas. Prefiero ser como el pintor que plasma algo en el lienzo a través del pincel, en esto caso yo lo hago a través de la cámara y lo reflejo en la pantalla.

R.A.S.: Volviendo a Bolívar en Manuela Sáenz... El delirio también es el reflejo de la vida del Libertador, en este caso lo mezclaste mucho más a través de la introspección en la que el papel de Manuela transita durante los momentos en los que la imagen de Bolívar es rememorada. Fíjate, se puede observar como Manuela alucina durante casi todo el film. El mismo tipo de propuesta que hiciste en Bolívar Sinfonía Tropikal (1980) a través del Libertador y el Dr. 
Reverend frente a la playa; finalmente, en tu película Reveròn (2011), también incluyes la locura y la alucinación a través del Pintor Armando Reverón. ¿Qué te ideó el uso de la locura como hilo conductor de la trama?

D.R.: La psicología primordialmente. La psicología de mis personajes es algo que yo profundizo mucho, paso mucho tiempo estudiando los detalles de mis personajes y en el caso de Manuela, la historia lo narra, Manuela terminó enloquecida en Paita, enferma, pensando en Bolívar. A través de ella entendemos la historia de su Bolívar, del Libertador que ella conoció. Con una trama mucho más efervescente, más apasionada, sin embargo, es a través de esa locura como el espectador puede asimilar el dolor de Manuela, la reflexión sobre sí misma y lo que sintió cuando Bolívar partió al exilio sin ella. En el caso de Simón Bolívar en la Sinfonía Tropikal, el Dr. Reverend, médico de cabecera del Libertador, es el receptor de las alucinaciones de Bolívar. Este film es un poco más difícil de interpretar, sin embargo, se puede observar claramente que Bolívar rememora su pasado, su gloria, los hechos más importantes de su vida y los paisajes que observó, uno a uno yo puse todos esos detalles allí, lo que sucede es que es muy complicado entenderlos si no se conoce bien lo que pasó durante la época de la independencia venezolana. Con la película Reveròn, ocurre algo similar. Fíjate, Reverón era muy conocido por su arte y por su obsesión con la luz, y públicamente por su locura, por su infinita creatividad llena de cosas nunca antes vistas en la sociedad caraqueña. Por esto, la vida de Reverón que reflejé en la película transita también en una trama que fusiona la creatividad artística, el romance con Juana, la vida en el castillete y el final en el manicomio en donde Reverón se reencuentra a sí mismo y se refugia en su pintura. El final del film condensa todo esto cuando él pinta una palmera en una pared en el patio del sanatorio. En fin, la alucinación de mis personajes es el puente que conecta los eventos que vivieron y que pueden ser detallados como si se narraran los sueños, los recuerdos que motivan dichas historias. Así pasa con el final en Manuela Saénz... ella muere alucinando, viendo a Bolívar en una hamaca recitándole unas palabras que el mismo Bolívar le escribió en una carta. Al final, la película termina con una escena que muestra las cartas de Bolívar quemándose en una hoguera y Manuela, subliminalmente anuncia su muerte vestida de Libertadora caminando rumbo al mar.

R.A.S.: Gracias, Diego. Gracias por revelar tantos datos interesantes sobre la imagen de Bolívar y sobre tus otras películas.

D.R.: De nada. Te daré unas fotos para que veas cómo fue que se originaron estas ideas hace muchísimos años cuando yo apenas pensaba en hacer mis películas que poco a poco pude ir realizando. 
R.A.S.: Excelente. Las utilizaré en esta entrevista.

Nota final: Diego Rísquez compartió conmigo gran parte de su archivo personal de fotografía, artes plásticas y cinematografía. Rísquez falleció en Caracas el 13 de enero del año 2018.

\section{Imágenes del archivo personal de Diego Rísquez}

1. Esta fotografía refleja los inicios del mismo Rísquez posando para futuras escenas. D.R.: Aquí puedes ver el modelo de traje de campaña del Libertador. En mi película Manuela Sáenz, la actriz Beatriz Valdez posa de la misma manera frente al mar en la escena final del film. Manuela viste el mismo tipo de uniforme como la Libertadora del Libertador.

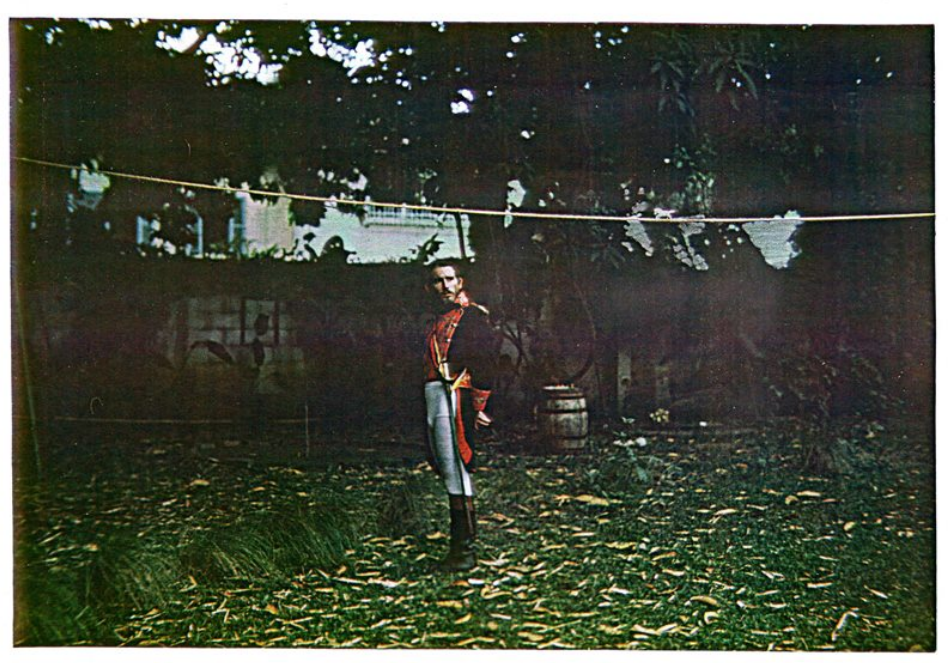


2. Con esta fotografía Diego Rísquez recuerda su escena del mensajero que le da la carta que anuncia la muerte de Simón Bolívar a Manuela Sáenz. D.R.: En la película Manuela Sáenz...yo soy el mensajero que trae la carta del general O'Leary que anuncia la muerte del Libertador. Esta fotografía es de la época de mi trilogía, sin embargo, forma parte de varias ideas utilizadas en muchas escenas con Bolívar y con Manuela.

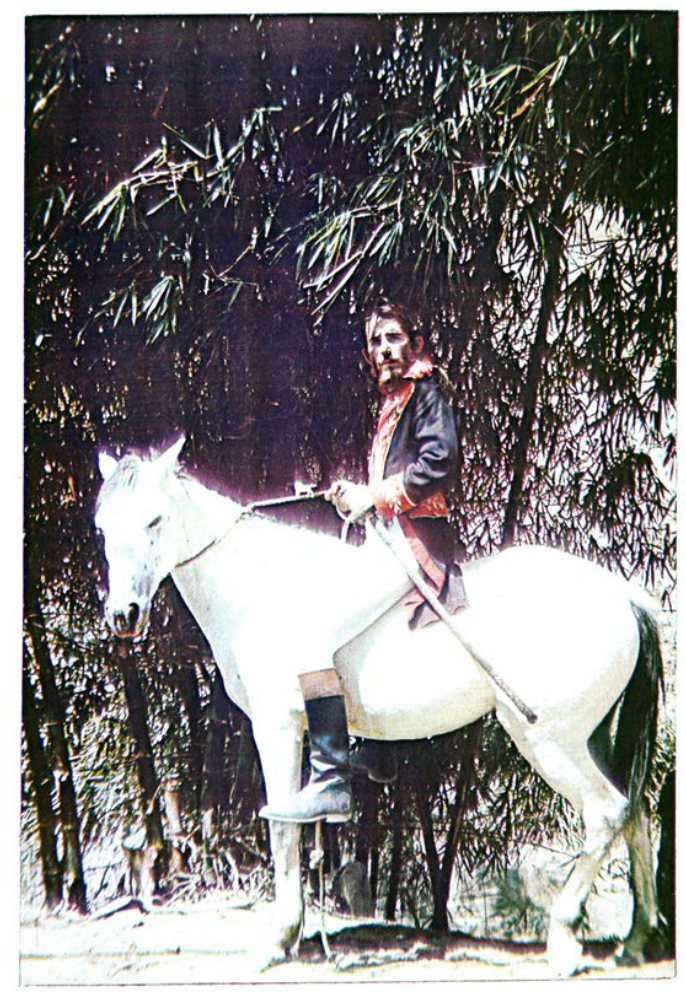


3. En el caso de los paisajes, las escenas y la permanente presencia del mar, Diego me comentó su afición por la playa, por los colores y el sonido de las olas. D.R.: Aquí puedes ver mis primeros pasos cuando ideaba el comienzo de mis películas: Bolívar Sinfonía Tropikal y Manuela Sáenz, comparten un comienzo similar en donde el mar inicia, transita y finaliza las películas.

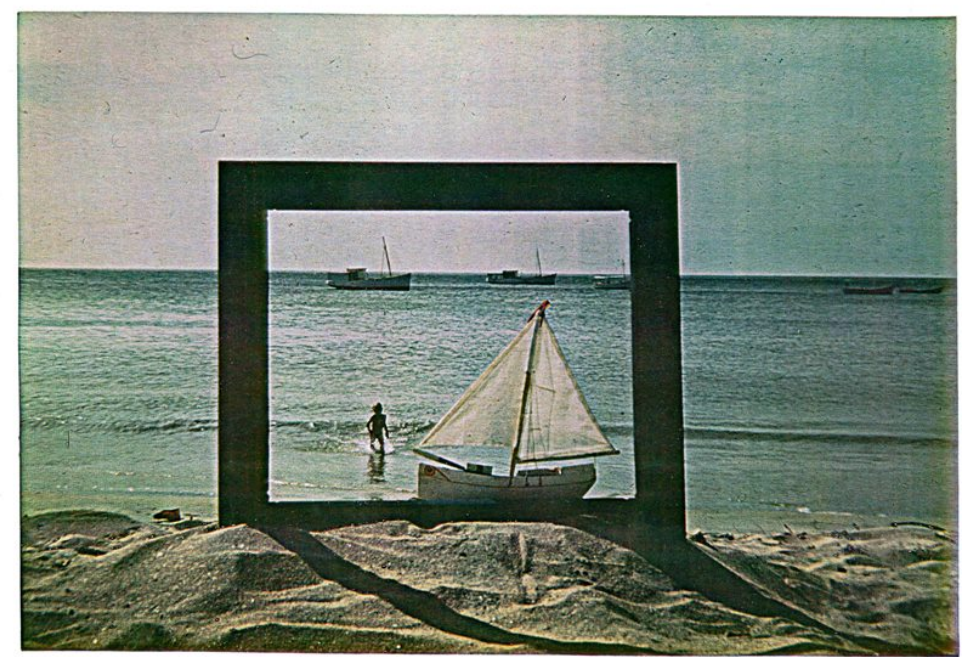


4. Diego compartió conmigo una serie de fotografías que le dieron vida a su penúltima película titulada Reveròn (2011) durante una charla que tuvimos sobre este film. D.R.: En esta foto puedes ver mis primeras ideas sobre un film basado en la vida de Armando Reverón. Esta imagen también la llevé a la gran pantalla años después.

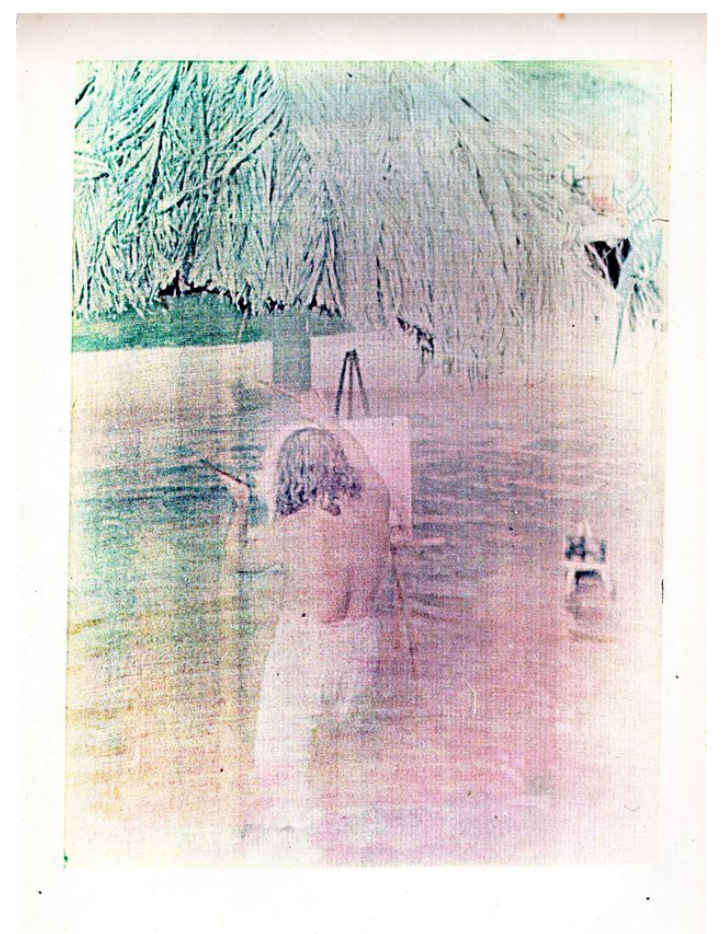

